\title{
AC 2008-178: WHAT PLACE ENGINEERING CODES AND STANDARDS HAVE IN UNDERGRADUATE ENGINEERING CURRICULA?
}

\section{Tongele Tongele, Southern Illinois University, Edwardsville}

Dr. Tongele received a BS in mechanical engineering from the California State Polytechnic University Pomona in 1995. He completed his MS and PhD in mechanical engineering at the Catholic University of America in Washington, DC, in 2001 and 2003 respectively. After working for the government of the District of Columbia, Washington, DC, in the Department of Health, Environmental Health Administration, Bureau of Environmental Quality, from 2001 to 2004, Dr. Tongele joined the faculty in the Department of Mechanical and Industrial Engineering at Southern Illinois University Edwardsville, in the August of 2004. Dr. Tongele's areas of research include Theory of Elasticity, Structural Mechanics, Design, and Engineering Education. 


\begin{abstract}
How effectively are future engineers exposed to codes, standards, and technical regulations that influence design and manufacturing or construction? How well are future engineers aware of the importance of codes and standards for the effectiveness, the reliability, and the safety of products designed and manufactured in the United States (US) as well as products imported to the US? Using the school of engineering at Southern Illinois University Edwardsville as a case study, this paper explores how engineering codes and standards are included in academic curricula. A suggestion is made regarding how academic institutions can collaborate with professional societies and industries as well as government agencies to further the exposure of future engineers to engineering codes and standards.
\end{abstract}

\title{
1. Introduction
}

It is well known that it was until 2000 that the Accreditation Board for Engineering and Technology (ABET), under criterion 4, titled "Professional Components," that students are required to incorporate engineering standards in design experience: "Students must be prepared for engineering practice through the curriculum culminating in a major design experience based on the knowledge and skills acquired in earlier coursework and incorporating engineering standards and realistic constraints that include most of the following considerations: economic; environmental; sustainability; manufacturability; ethical; health and safety; social; and political." In the new ABET criteria for accrediting engineering programs during the 2008-2009 accreditation cycle, it is under criterion 5, explicitly titled "Curriculum", that the requirement for using engineering standards is placed - in these terms: "Students must be prepared for engineering practice through a curriculum culminating in a major design experience based on the knowledge and skills acquired in earlier coursework and incorporating appropriate engineering standards and multiple realistic constraints." 2 What is obvious here is that ABET consistently requires that engineering programs through their curricula expose students to engineering standards.

In the Introduction to ASME Codes and Standards, a standard is defined as a set of technical definitions and guidelines - "how to" instructions for designers and manufacturers. Standards are considered voluntary because they serve as guidelines, and not have the force of law. A code is a standard that has been adopted by one or more government bodies and has the force of law, or when it has been incorporated into a business contract. ${ }^{3}$

In practice, it is because of codes and standards that in a movie theater, the projector in use is designed with parts that fit together and are easily replaced, chains and sprockets fir one another, plumbing fixtures are interchangeable, elevators do not fall, nuts and bolts have uniform dimensions, power generation equipment and industry in general operate safely and economically. Virtually all modern devices for personal improvement and amusement - radio, television set, VCR, telephone, computer, hand tools, and sports equipment - involve one or more engineering standards. ${ }^{3}$

How are engineering codes and standards incorporated into engineering programs and curricula? Using the School of Engineering at Southern Illinois University Edwardsville (SIUE) 
as a case study, this paper explores how engineering codes and standards are included in academic curricula, and suggests ways academic institutions can collaborate with professional societies and industries as well as government agencies to further the exposure of future engineers to engineering codes and standards.

\section{Incorporating Codes and Standards in Curricula}

\subsection{Where to Find Codes and Standards?}

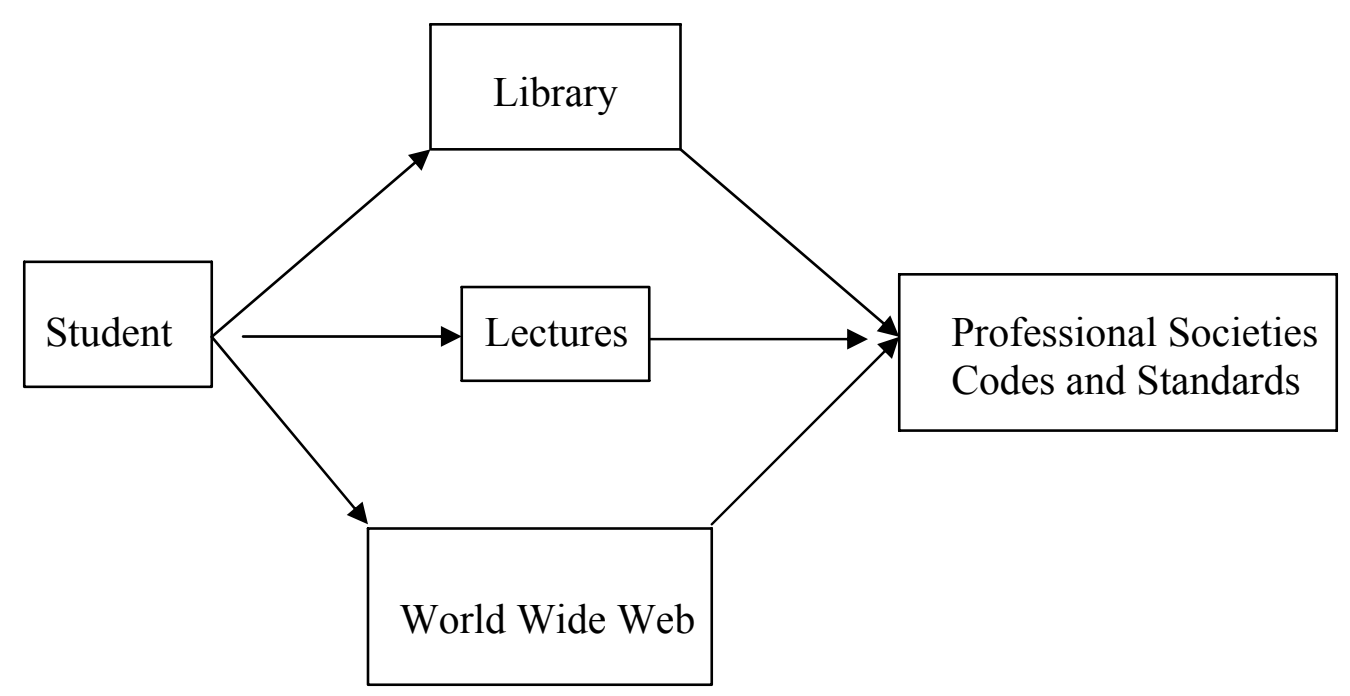

Figure 1 Student's paths to Codes and Standards

Figure 1 is an illustration of how students can get to engineering codes and standards and learn about them. It is shown that through class lectures, library and World Wide Web searches, students can find about engineering codes and standards as well as the professional societies that develop and maintain them.

The library at SIUE maintains a collection of handbook standards as well as direct access to Annual Book of ASTM Standards (Conshohocken, PA: ASTM, 1970- ... Ref. TA401.A653), IEEE Standards - 1,600 current and active IEEE standards available online in IEEE Xplore, and an Index and Directory of Industry Standards (Englewood, CO: Global Engineering Documents, 1989- . Ref. T59.2.U6I5 1998). The library also maintains links to Organizations and Societies, including the ones that develop and research standards and codes (ANSI: American National Standards Institute. — http://www.ansi.org/).

Based on Dr. Kelly's information search at the Massachusetts Institute of Technology (MIT) library web site, it is found that mechanical engineering students are directed to search the national standards network to determine if there is an American National Standard (ANS). MIT maintains a collection of all ANSI approved standards in its library, along with those of ASTM International (ASTM) and the Institute of Electrical and Electronic Engineers (IEEE) (electronic access). It also maintains Society of Automotive Engineers (SAE) aerospace and ground vehicle 
standards. ${ }^{4}$ It can therefore be assumed that it is within the reach of university libraries in the United States to maintain some collections of Codes and Standards as well as links to professional societies and organizations that develop standards.

Furthermore, nowadays students are known to be excellent World Wide Web navigators, and as such, could by themselves sail into professional society websites and access information available on codes and standards. If library tours and searches and class lectures introduce students to professional societies and organizations' codes and standards, then students can develop the taste and the desire to go by themselves, access and browse through codes and standards that maybe available online.

\subsection{A Process of Integrating Codes and Standards in Curricula}

What Figure 2 illustrates is a more formal way beyond library and World Wide Web of taking students to the acquaintance with codes and standards through the academic program. Ideally, when students arrive at a university campus as freshmen, they are taken on tours to introduce them to the university and its infrastructures, especially the library and how it works. These tours offer the first opportunity to tell students about standards and where to find them. One may ask: "do all universities conduct such tours? What is the percentage of freshmen that take part in these tours? Are there explicit references made to standards and codes during these tours?"

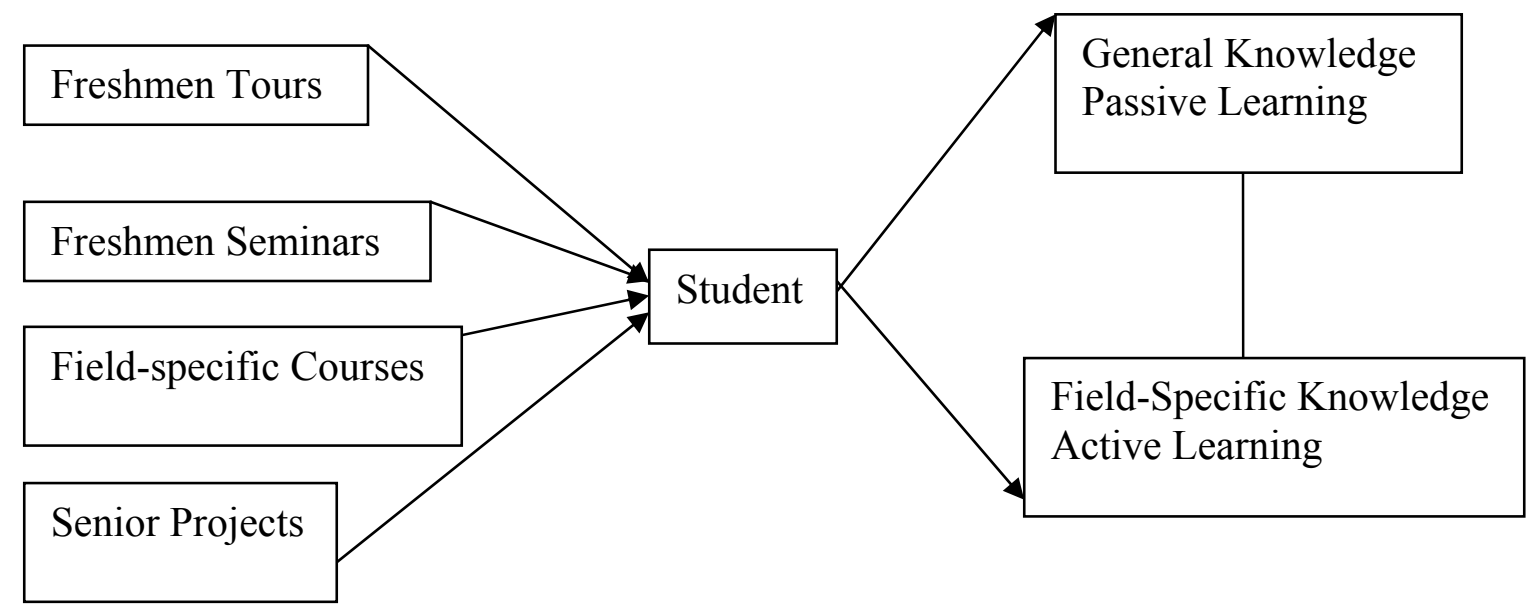

Figure 2 A Process of Exposing Students to Codes and Standards

Let's leave these questions right there for now, and remark that beyond the freshmen tours, there exist freshmen seminars conducted by engineering departments to introduce the newcomers to the field and profession of engineering. These seminars often talk about the obligations, rewards and ethical responsibilities that come with the profession of an engineer. These seminars could constitute a second opportunity for introducing new students to codes and standards and the professional societies that develop them. The questions asked above show up here as well: "Do these freshmen seminars actually talk about codes and standards?" 
Let's not be intrigued to attempt answering these questions, and observe that as students advance in their programs, there exist field-specific standards and codes to which they could be exposed. During course lectures, instructors could point to specific codes and standards, explain why and when are they required, and where they can be found. Instructors could assign class projects or homeworks that require students to consult handbooks for codes and standards. This could constitute the first opportunity for students to actually get to consult and use codes and standards and get a first hand feeling of them. At this point, students make the transition from passive introduction to codes and standards to active users of codes and standards. But the famous questions are present here as well: "Are students actually introduced to field-specific codes and standards during their progression through their programs?"

Once again, let's resist the temptation of trying the answer the questions, and note that when students become seniors and prepare to graduate, they must take capstone design courses and do senior projects. This looks like a last opportunity but a major opportunity for students to get in depth in the use of codes and standards. This certainly sounds like the "major design experience based on the knowledge and skills acquired in earlier coursework and incorporating appropriate engineering standards and multiple realistic constraints" required by ABET. But the questions remain relevant even up to this point: "Do students use in depth codes and standards in their capstone design or senior projects?"

There may not be an absolute yes or no to the questions asked throughout this section. A partial yes is however certain: students are exposed to codes and standards, but the degree of exposure depends upon the school and program. Several authors have written on the effort by universities, schools and programs to incorporate codes and standards in engineering design education. $^{5-8}$

\section{University Practices: SIUE Case Study}

As a Mechanical Engineering faculty member at SIUE (Southern Illinois University Edwardsville) who has taught and teaches undergraduate capstone design and design of machine elements, I sought to investigate practices related to the exposure of students to codes and standards not only in Mechanical Engineering Department, but in other departments of the School of Engineering as well. These departments include Civil Engineering (CE), Construction Management (CM), Electrical and Computer Engineering (ECE), Industrial and Manufacturing Engineering (IME), and Mechanical Engineering (ME). Based on investigations conducted with faculty teaching courses where codes and standards are or could be mentioned as well as some department chairs, the following results graphically presented were obtained. These figures shows the level of students' exposure to codes and standards on a scale of zero through 10, zero being little or no exposure and 10 being maximum exposure. Figure 3, 4, and 5 show the level of student s' exposure to codes and standards during the freshmen seminar, field-specific courses, and senior projects respectively. 


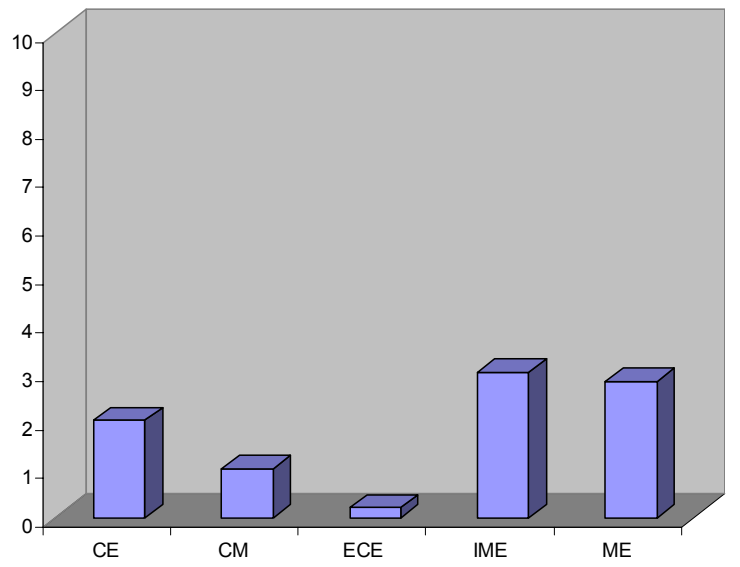

Figure 3 Freshmen Seminar

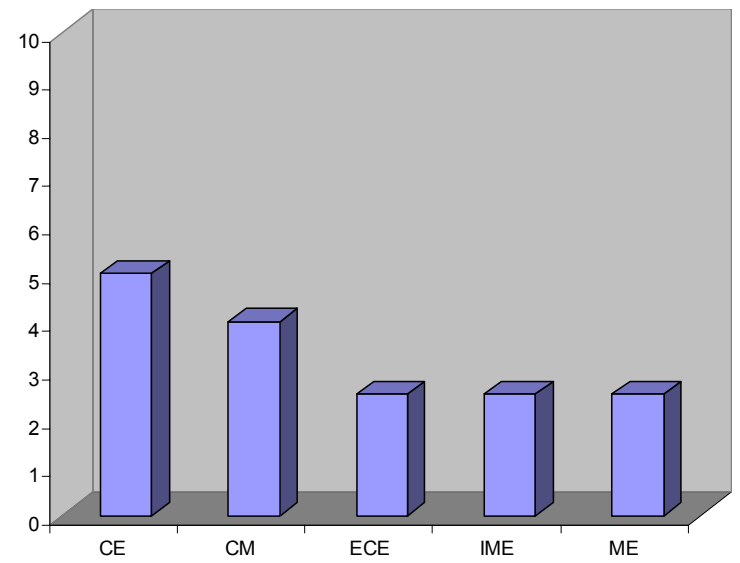

Figure 5 Senior Project

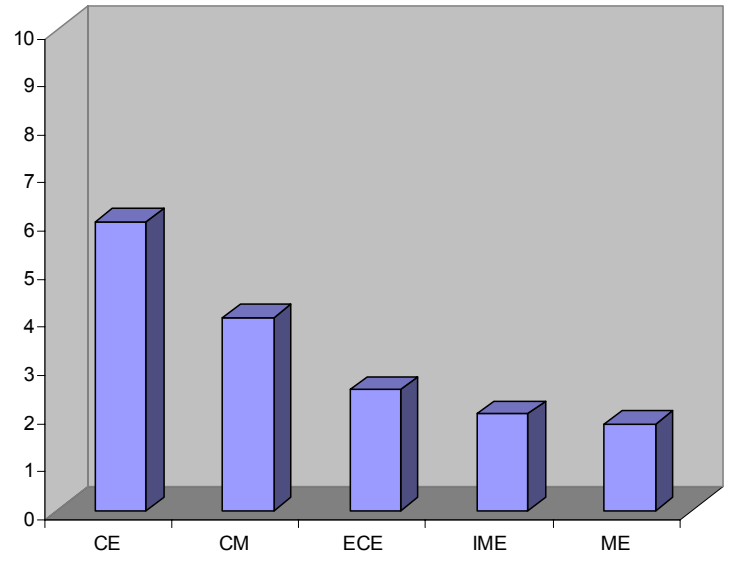

Figure 4 Field-specific Courses

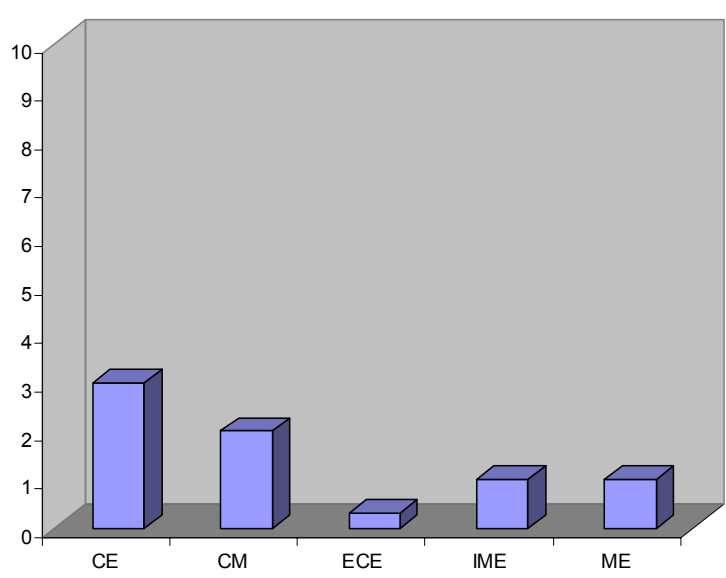

Figure 6 Amount of Classroom Time Used

Figure 3 shows that the ECE are likely not to be exposed to issues related to codes and standards during freshmen seminars. IME and ME students seem to get more exposure to the issues during the freshmen seminars. When it comes to field-specific courses, Figure 4 indicates that $\mathrm{CE}$ and $\mathrm{CM}$ students are better exposed to issues of codes and standards compare to their counterpart in ECE, IME and ME departments. Figure 5 shows that CE students, followed by $\mathrm{CM}$ students apply or make use of codes and standards in their senior projects more than their counterpart in ECE, IME and ME departments. When the issues of codes and standards are dealt with in the classroom, very little time is spent on it in ECE department, and more time is spent by the CE department (Figure 6). What all these figures clearly show is that none of the departments get students to maximum exposure to the issues of codes and standards. Only CE department exposure its students to codes and standards issues above the average during its fieldspecific courses as shown in figure 4 . 


\section{Listening to Employers and Industry Leaders}

Engineering students are prepared to enter the work and contribute to society. They are employed as technical personnel, research and development engineers, quality control engineers, managers, etc. It is therefore important to know what employers and industry leaders are looking for in graduating engineers, what they expect from engineers crossing from the academia to industry, and what they think or say when it comes to knowledge of codes and standards. As coordinator of the mechanical engineering industry outreach program, which is part of the SIUE school of engineering broader program known under the acronym of IPAC (Industry and Professional Advisory Committee), and as instructor of capstone design for mechanical engineering department where the final product is evaluated and judged by a panel of professional industry engineers and leaders, I have on several occasions engaged employers and industry leaders with specific questions such as "What are you looking for in our graduating engineers? What do you think of our graduates' knowledge of codes and standards?" Table 1 is a compilation of qualities and traits (not in a special order) employers and recruiters seek in graduating engineers. Employers and recruiters were asked to assign level of importance to these qualities, one hundred meaning very important, and zero meaning unimportant; their responses are presented in Figure 7.

\begin{tabular}{|c|l|}
\hline Numbering & Quality/trait \\
\hline 1 & Intellectual ability/Technical skills \\
\hline 2 & Communication skills \\
\hline 3 & Interpersonal skills \\
\hline 4 & Integrity/Credibility \\
\hline 5 & Reliability/Get-it-done attitude \\
\hline 6 & Creativity \\
\hline 7 & Enthusiasm and energy \\
\hline 8 & Affordable \\
\hline 9 & Trainable \\
\hline 10 & Codes and Standards \\
\hline
\end{tabular}

Table 1 Qualities Employers Seek in Graduating Engineers

Figure 7 shows that competency expressed through intellectual ability and technical skills as well as integrity and credibility rank above other qualities. The knowledge of codes and standards ranks far below other qualities. This ranking seems justified by what representatives from Boeing and Caterpillar once told me. They said that their companies do not assign newly hired college graduate tasks that require the use of codes and standards. These tasks are given to more experienced engineers who have been with the companies for years and are very familiar with the company's practices as related to codes and standards as well as legal affairs. The new engineers are placed under the mentorship of the more experienced ones to become more mature within the company and more knowledgeable of the company practices, codes and standards. It is only then that they are assigned to tasks that involve the use of codes and standards. 


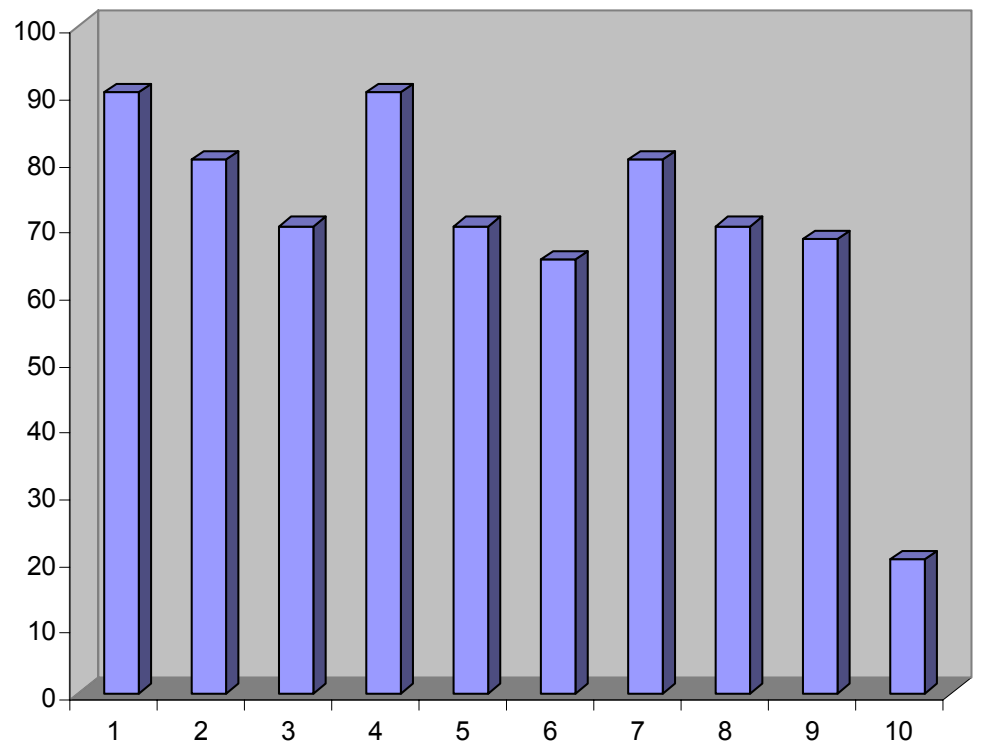

Figure 7 Degree of Importance Employers Give to these Qualities

It does not look like most employers and industry leaders consider the knowledge of codes and standards as essential requirement for hiring engineers and expecting best performance out of them. With this in mind, the best ways to use in exposing students to codes and standards may widely vary in importance and urgency from one program to another.

\section{Toward Creating Best Practices}

Figure 8 is an illustration of elements to be taken into account when attempting to create engineering curricula that incorporate engineering to codes and standards. Although the degree of importance and urgency concerning the exposure of engineering students to engineering codes and standards may vary with schools, programs, and industry needs, the importance of introducing engineering students to codes and standards cannot be completely ignored. Referring to the section on "A Process of Integrating Codes and Standards in Curricula," it can be suggested that depending on specific programs, there could be multiple practices equally good for exposing students to codes and standards. One way might be to use specific courses to focus on codes and standards, another way might be to touch on codes and standards throughout program courses, another way might be to have students learn about and applied codes and standards in their senior year using senior projects or capstone design courses, another way could be through seminars by and collaboration with professional societies that develop and maintain standards, etc. 


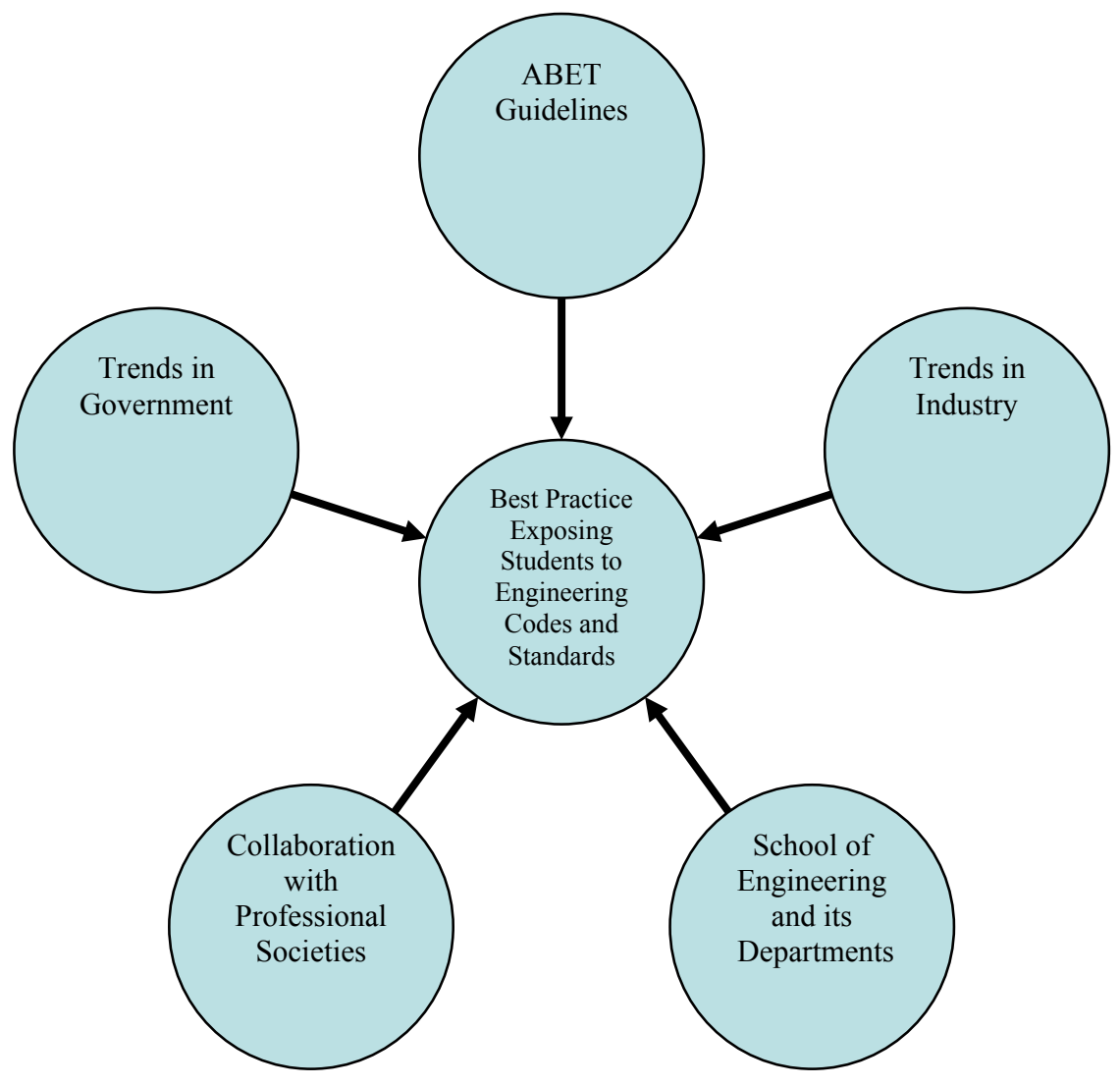

Figure 8 Elements for Creating Curricula that Incorporate Codes and Standards

\section{Conclusion}

After looking into the world of codes and standards and the teachings related to codes and standards in engineering institutions, it can be remarked that the problem is not in the lack of materials readily available to assist faculty in including engineering standards programs and curricula. The problem may essentially reside in the need or lack of need felt by engineering programs and institutions to include codes and standards in their curricula.

Engineering programs that make conscious decision to include standards in their curricula have more than one opportunity to do so; these opportunities include freshmen seminars and guided university tours, field-specific courses, capstone design courses and senior projects.

More workshops, seminars and conferences are needed to focus particularly on the importance of finding places in engineering curricula to incorporate codes and standards. 


\section{Bibliography}

1. ABET, "Criteria for Accrediting Programs in Engineering in the United States," Engineering Criteria 2000, $3^{\text {rd }}$ edition.

2. ABET, "Criteria for Accrediting Engineering Programs," Effective for Evaluation During the 2008-2009 Accreditation Cycle.

3. ASME International, "Introduction to ASME Codes and Standards." Viewed at http://files.asme.org/ASMEORG/Codes/About/Links/1028.pdf

4. Kelly, W. E. (2003), "Incorporating Engineering Standards in the Major Design Experience," 2003 ASEE

Annual Conference and Exposition: Staying in Tune with Engineering Education, pp.2887-2894, June 22-25, 2003, Nashville, TN, USA.

5. Kelly, W. E. (2005), "Incorporating Standards in Capstone Design Courses," 2005 ASEE Annual Conference and Exposition: The Changing Landscape of Engineering and Technology Education in a Global World, pp.7841-7850, June 12-15, 2005, Portland, OR, USA.

6. Kelly, W. E. (2008), "Standards in Civil Engineering Design Education," Journal of Professional Issues in Engineering Education Practice, vol.134, n.1, pp.59-66.

7. Gerhart, P., Gerhart, A., Cain, B. (2007), "Using ASME Performance Test Code in the Undergraduate Mechanical Engineering Curriculum," 2007 ASEE Annual Conference and Exposition, June 24-27, 2007, Honolulu, HI, USA.

8. Tongele, T.N. (2007), "Bridging the Gap between Academia and Industry through Capstone Design," National Capstone Design Course Conference, June 13-15, 2007, Boulder, CO, USA. 